(RESEARCH ARTICLE)

\title{
Correlative antimicrobial assay of various foreign toothpaste against oral microbial isolates
} \author{
Ayomikun ${ }^{3}$ \\ ${ }^{1}$ Department of Science Laboratory Technology, Auchi Polytechnic, Auchi, Edo State, Nigeria. \\ 2 Department of Biological Science, Niger State Polytechnic, Zungeru, Niger State, Nigeria. \\ ${ }^{3}$ Department of Microbiology, University of Abuja, FCT, Abuja, Nigeria.
}

Oleghe Peace Omoikhudu ${ }^{1}$, Agholor Kin ${ }^{2,}{ }^{*}$, Olusola Lucy Fatima ${ }^{2}$, Abubakar Idris ${ }^{2}$ and Orhewere Victory

Publication history: Received on 07 July 2020; revised on 18 July 2020; accepted on 21 July 2020

Article DOI: https://doi.org/10.30574/wjarr.2020.7.1.0249

\begin{abstract}
The in-vitro antimicrobial assay of four (4) foreign toothpastes sold in Nigeria viz; Sensodyne ${ }^{\circledR}$, Raiya ${ }^{\circledR}$, Mentadent ${ }^{\circledR}$ and Colgate $^{\circledR}$ were carried out using agar well diffusion method against eight (8) oral clinical isolates which include the strains of Streptococcus mutans, Brahamella catarrhalis, Veillonella spp, Micrococcus luteus, Lactobacillus spp, Staphylococcus aureus, Streptococcus pneumoniae, and Candida albicans. The statistical analysis was done using SPSS windows, by applying mean value, T-test, analysis of variance (ANOVA) with Post-hoc least significant differences (LSD) method $(\alpha=0.05)$. The result showed that based on the mean diameter of the zone of microbial inhibition produced by the toothpaste in agar well diffusion method, Mentadent ${ }^{\circledR}$ showed maximum zone of inhibition against the entire test organisms with Streptococcus pneumoniae being the most inhibited (sig< 0.01 ) compared to all other toothpaste formulations. Colgate ${ }^{\circledR}$ gave the least antimicrobial activity, whereas Micrococcus luteus was the least inhibited among the eight (8) isolates. Although all the toothpaste selected for this study had antimicrobial properties, Mentadent ${ }^{\circledR}$ distinguish itself because of its improved formulation of $2 \%$ zinc citrate. There is an urgent need for toothpaste manufacturers to periodically review their formulations in order to improve the oral health of its users.
\end{abstract}

Keywords: Antimicrobial activity; Toothpaste; Oral microbes; Zone of inhibition

\section{Introduction}

Toothpaste is a gel or powder dentifrice used with toothbrush to clean and maintain the aesthetic and health of teeth [1]. It is used to promote oral hygiene and to prevent tooth decay as it aids in the removal of dental plaque and food particles from the teeth. It also assists in suppressing halitosis and delivers active ingredients such as xylitol and fluoride to the mouth that prevent tooth and gum disease (Gingivitis). Toothpaste has been used since antiquity [2] and is one of the main dispensable elements of Oral health care [3].

The production of toothpastes started in India and China about 300-500BC. Initially, crushed bone and crushed egg shells were formally used as an abrasive in tooth for Oral health care [4]. Modern toothpastes contain emulsifying agents such as sodium lauryl sulphate [5] and essentials oils, such as Eucapol, Menthol and Thymol, frequently used as flavour which also contribute to the antiseptic property of the products [6]. These substances kill microorganisms by disrupting their activity, prevents bacterial aggression and slows bacterial multiplication [7].

Toothpastes are designed and formulated to solve dental problems such as cavity plaque, gingivitis, tartar and to prevent fluorosis in children. They also ensure tooth whitening, tooth sensitivity and control fresh breath. They are classified as drug because they contain active ingredients that maintain a balance in each person's oral microbial population and prevent opportunistic microorganisms (which can proliferate when the balance is lost) and initiate

\footnotetext{
* Corresponding author: Agholor Kin, +2347062361650, kinagholor@gmail.com
} 
disease process [8]. Toothpaste usually contains active ingredients, the first active ingredients included fluoride which improves the health of the teeth and helps the tooth enamel to resist cavities and decay [2]. It also helps the enamel to remain strong so that it can resist acid producing oral bacteria when sugary foods are eaten [4]. Other therapeutic agents that may be added to toothpaste includes Potassium nitrate, Pyrophosphate or zinc citrate, Triclosan and stannous fluoride. Potassium nitrate is used to treat dental hypersensitivity, Pyrophosphate or zinc citrate prevents tartar build up, and various abrasives or enzymes, to help whitening teeth while Triclosan and stannous fluoride reduce gingival inflammation [5].

The selection of appropriate toothpaste may provide a positive influence on the prevention of allergic reactions and tooth decay [3]. Since fluoride is not the only active ingredient in toothpaste, other important factors considered when selecting a toothpaste are the cleaning abilities of toothpastes as provided by abrasives [9], the antimicrobial qualities, which in turn are provided by a variety of substance with different abilities to inhibit the growth of germs in oral cavity [10], as well as a number of ingredients with specific purpose to solve specific problems. However, the wide selection of various ingredients make it difficult for patient to choose the proper toothpaste and complicated by the endorsement of dental product by professionals. Therefore, this study was aimed at determining the antimicrobial quality of different toothpaste to ascertain their effectiveness in reducing oral bacteria and destroying oral pathogenic microbes in order to improve dental health.

\section{Material and methods}

\section{$2.1 \quad$ Sample collection}

The toothpaste samples used for this study where purchased commercially from toothpaste vendors in New Benin market, Benin-City, Edo State, Nigeria. Four foreign toothpaste were used in all, these include: Colgate ${ }^{\circledR}$, Mentadent ${ }^{\circledR}$, Raiya ${ }^{\circledR}$ and Sensodyne ${ }^{\circledR}$ as shown in table 1 . The samples were kept at room temperature and were analyzed within one week of collection.

Table 1 Sample of selected toothpaste with their active ingredients

\begin{tabular}{|l|l|l|}
\hline Toothpaste sample & Foreign toothpaste & Active ingredient \\
\hline Sample 1 & Sensodyne ${ }^{\circledR}$ & Sodium fluoride $0.315 \% \mathrm{w} / \mathrm{w}$ \\
\hline Sample 2 & Mentadent ${ }^{\circledR}$ & Sodium fluoride $0.32 \%$ and zinc citrate $2 \%$ \\
\hline Sample 3 & Raiya $\AA$ & Sodium monofluorophosphate $0.84 \% \mathrm{w} / \mathrm{w}$ \\
\hline Sample 4 & Colgate $\AA$ & Sodium monofluorophosphate $1.1 \% \mathrm{w} / \mathrm{w}$ \\
\hline
\end{tabular}

\subsubsection{Collection of test organisms}

Strains of Streptococcus mutans, Branhamella catarrhlis, Veillonella spp, Micrococcus lutteus, Lactobacillus spp, Staphylococcus aureus, Streptococcus pneumoniae and Candida albicans were used for these study. The pure isolates of these organisms were obtained from the oral cavities of healthy young informed-consenting adults and confirmed using standard cultural, morphological and biochemical characteristics [11] [12]. They were kept and sustained in the Microbiology Laboratory unit of Auchi Polytechnic, Auchi, Edo State in appropriate agar slants.

\subsection{Sample preparation}

$1 \mathrm{~g}$ of each foreign toothpaste sample was weighed and dissolved in $10 \mathrm{ml}$ of sterile water to make the stock solution.

\subsection{Culture media}

General purpose nutrient media, enrichment medium and other appropriate selection media were employed in the subculturing and conformation of specific organisms used in the study which include: Nutrient agar, Blood agar, Mannitol salt agar, Muller Hilton (LAB. M. England), peptone water (Oxoid, England) etc. They were all prepared according to manufacturer's specifications. 


\subsection{Assessment of antimicrobial effect using agar well method}

The test organisms were sub-cultured into their appropriate broth cultures for 3 hours. The turbid broth was diluted and standardized to be equivalent to $0.5 \mathrm{McF}$ arland standard. Thereafter, $0.02 \mathrm{ml}$ of each of the test organism were immediately transferred into the Petri-dish before $20 \mathrm{ml}$ of Muller Hilton agar was added, mixed by swirling and allow to solidify. A standard cork borer measuring $6 \mathrm{~mm}$ diameter was used to make the agar well. Thereafter, $0.1 \mathrm{ml}$ of the prepared dilution of each foreign toothpaste sample was introduced onto the seeded plates in triplicates using a syringe, the plates were labelled accordingly and allowed to stand for 30 minutes to allow for diffusion. The plates were incubated at $37^{\circ} \mathrm{C}$ for 24 hours and their inhibition zone diameters were obtained in cm using ruler.

\section{Results and discussion}

Table 2 Confirmatory biochemical characterization of the microbial isolates

\begin{tabular}{|l|l|l|l|l|l|l|l|l|l|}
\hline \multicolumn{7}{|l|}{ Biochemical characteristic } & \multicolumn{2}{l|}{ Oral clinical isolates } \\
\hline Gram rxn & Mot. & Cat. & Coag. & Oxid. & Indole & Methylred & Ur & Nitrate & \\
\hline+ & - & + & + & - & - & - & - & ND & Streptococcus mutans \\
\hline- & - & + & ND & + & ND & ND & ND & ND & Branhamella catarrhalis \\
\hline- & - & - & ND & + & - & ND & - & + & Veillonella spp \\
\hline+ & - & + & - & ND & ND & ND & - & - & Micrococcus luteus \\
\hline+ & - & - & ND & - & - & - & - & - & Lactobacillus spp \\
\hline+ & - & + & + & - & - & + & + & + & Staphylococcus aureus \\
\hline+ & - & - & ND & - & ND & ND & - & ND & Streptococcus \\
\hline ND & ND & ND & ND & ND & ND & ND & ND & ND & Candida albicans \\
\hline
\end{tabular}

Keys: + = present, - = Absent, Mot.= Motility, Oxid= Oxidase,Ur= Urase, Cat.=Catalase, Coag.=Coagulase ND = not determined Ur $=$ Urease

Table 3 Sample analysis of variance

\begin{tabular}{cccc}
\hline & & Value Label & $\mathbf{N}$ \\
\hline \multirow{2}{*}{ Experimental sample } & 1.00 & Sample 1 & 8 \\
& 2.00 & Sample 2 & 8 \\
& 3.00 & Sample 3 & 8 \\
& 4.00 & Sample 4 & 8 \\
& 1.00 & Streptococcus mutans & 4 \\
& 2.00 & Branhamella catarrhalis & 4 \\
& 3.00 & Veillonella spp & 4 \\
& 4.00 & Micrococcus luteus & 4 \\
& 5.00 & Lactobacillus spp & 4 \\
& 6.00 & Staphylococcus aureus & 4 \\
& 7.00 & Streptococcus pneumoniae & 4 \\
& 8.00 & Candida albicans & 4 \\
\hline
\end{tabular}


Table 4 ANOVA Result

\begin{tabular}{lcccccc}
\hline Source & Type I Sum of Squares & Df & Mean Square & F & Sig. & Partial Eta Squared \\
\hline Sample & .182 & 3 & .061 & .572 & .640 & .076 \\
Organism & 8.018 & 7 & 1.145 & 10.777 & .000 & .782 \\
Error & 2.232 & 21 & .106 & & & \\
Corrected Total & 10.432 & 31 & &
\end{tabular}

The ANOVA shows that the organisms are not statistically significant at sig greater 0.01 at $1 \%$. R-Square measures the accuracy of the experiment. The value of R-square is 0.786 indicating the samples experiment and organism for inhibition diameter is accurate $78.6 \%$. Adj r-square value of 0.684 implies the inhibition zone diameter explained the samples and organisms chosen for the experiment.

Table 5 Estimated marginal means

\begin{tabular}{lllll}
\hline Experimental Sample & Mean & Std. Error & \multicolumn{2}{c}{$\mathbf{9 5 \%}$ Confidence Interval } \\
\cline { 4 - 5 } & & & Lower Bound & Upper Bound \\
\hline Sample 1 & 1.156 & .115 & .917 & 1.396 \\
Sample 2 & 1.204 & .115 & .964 & 1.443 \\
Sample 3 & 1.129 & .115 & .889 & 1.368 \\
Sample 4 & 1.000 & .115 & .760 & 1.240 \\
\hline \multicolumn{5}{r}{} \\
\cline { 2 - 4 }
\end{tabular}

The best sample against the test organism had the highest mean and confidence interval values respectively. Therefore from this study, among the four samples selected, sample 2 had the highest mean value of 1.204 and highest inhibition zone diameter.

Table 6 Homogeneous subset

\begin{tabular}{cccc}
\hline Experimental Sample & N & Subset \\
\cline { 3 - 4 } & Sample 4 & 8 & 1.0000 \\
\hline \multirow{2}{*}{ Duncan $^{\mathrm{a}, \mathrm{b}}$} & Sample 3 & 8 & 1.1288 \\
& Sample 1 & 8 & 1.1563 \\
& Sample 2 & 8 & 1.2038 \\
& Sig. & & .265 \\
\hline
\end{tabular}

Means for groups in homogeneous subsets are displayed. Based on observed means. The error term is mean square (Error) $=.106$ a. Uses Harmonic Mean Sample Size $=8.000$. b. Alpha $=.05$. Inhabitation zone diameters $\left(\mathrm{cm}^{3}\right)$ 
Table 7 Subject factors

\begin{tabular}{|c|c|c|c|}
\hline & & Value Label & $\mathbf{N}$ \\
\hline \multirow{4}{*}{ Tooth Paste } & 1.00 & FPA & 8 \\
\hline & 2.00 & FPB & 8 \\
\hline & 3.00 & FPC & 8 \\
\hline & 4.00 & FPD & 8 \\
\hline \multirow{8}{*}{ Organism } & 1.00 & Streptococcus mutans & 4 \\
\hline & 2.00 & Branhamella catarrhalis & 4 \\
\hline & 3.00 & Veillonella spp & 4 \\
\hline & 4.00 & Micrococcus luteus & 4 \\
\hline & 5.00 & Lactobacillus spp & 4 \\
\hline & 6.00 & Staphylococcus aureus & 4 \\
\hline & 7.00 & Streptococcus pneumoniae & 4 \\
\hline & 8.00 & Candida albicans & 4 \\
\hline
\end{tabular}

Table 8 Subject effects

\begin{tabular}{lcccccc}
\hline Source & Type I Sum of Squares & Df & Mean Square & F & Sig. & Partial Eta Squared \\
\hline Samples & 3.383 & 3 & 1.128 & 3.924 & .023 & .359 \\
Anti & 4.020 & 7 & .574 & 1.998 & .104 & .400 \\
Error & 6.035 & 21 & .287 & & & \\
Corrected Total & 13.437 & 31 & & & \\
\hline \multicolumn{5}{r}{ R Squared $=.551$ (Adjusted R Squared = .337) }
\end{tabular}

The ANOVA shows that the organisms are not statistically significant at sig greater 0.01 at $1 \%$. This implies that the samples used on the experiment are different but the organism have the same inhibition diameter values. R-Square is measure the accuracy of the experiment the value of R-SQUARE is 0.551 indicates that the experiment of samples and organize for inhibition diameter is accurate 55.1\%. Adj R-Square value of 0.337 implies the inhibition zone diameter explained $33.7 \%$ samples and organisms chosen for the experiment.

Table 9 Organisms

\begin{tabular}{|c|c|c|c|c|}
\hline \multirow[t]{2}{*}{ Test Organisms } & \multirow[t]{2}{*}{ Mean } & \multirow[t]{2}{*}{ Std. Error } & \multicolumn{2}{|c|}{$95 \%$ confidence interval } \\
\hline & & & Lower Bound & Upper Bound \\
\hline Streptococcus mutans & 1.158 & .268 & .600 & 1.715 \\
\hline Branhamella catarrhalis & .525 & .268 & -.032 & 1.082 \\
\hline Veillonella spp. & .558 & .268 & .000 & 1.115 \\
\hline Micrococcus luteus & .250 & .268 & -.307 & .807 \\
\hline Lactobacillus spp. & 1.170 & .268 & .613 & 1.727 \\
\hline Staphylococcus aureus & .838 & .268 & .280 & 1.395 \\
\hline Streptococcus pneumoniae & 1.345 & .268 & .788 & 1.902 \\
\hline Candida albicans & .958 & .268 & .400 & 1.515 \\
\hline
\end{tabular}


Table 10 Post hoc tests

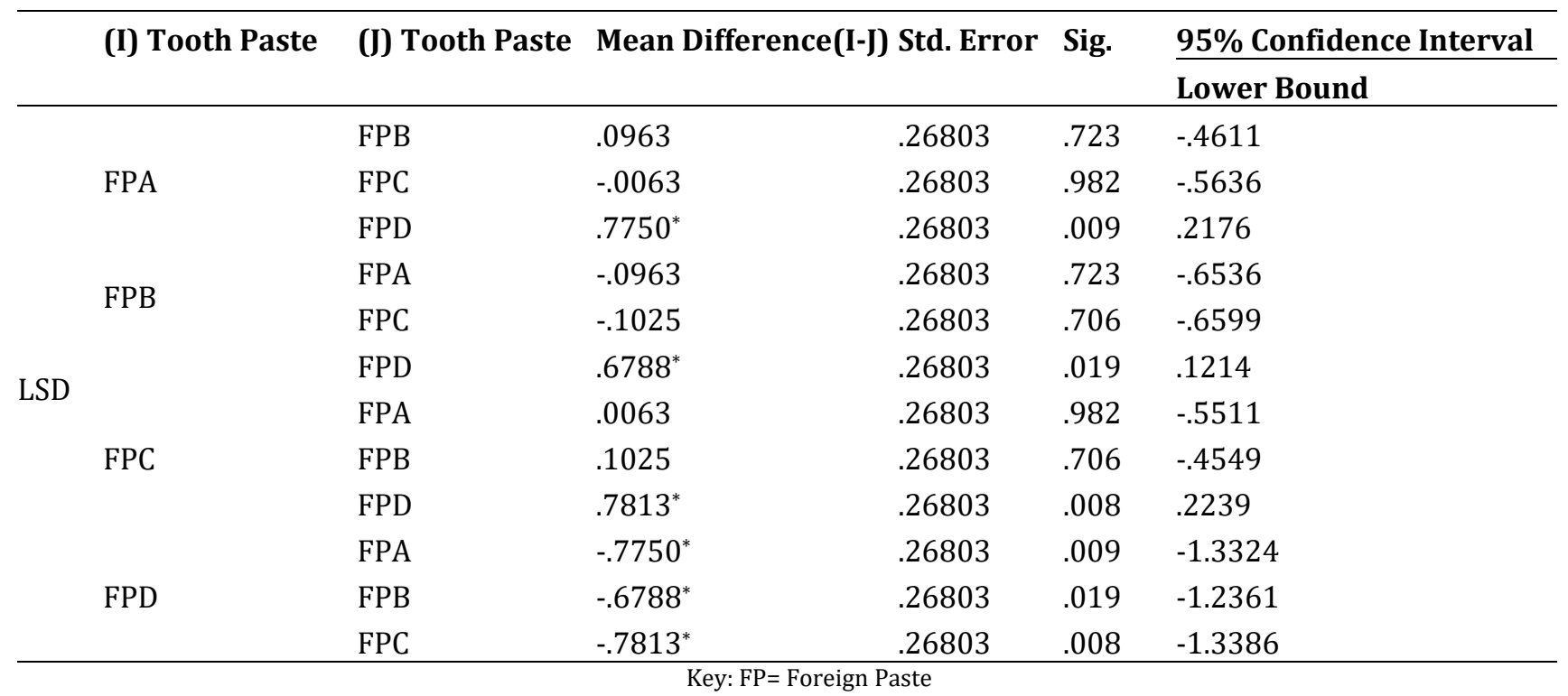

Toothpaste (multiple comparism) Dependent variable: inhibition zone diameters (cm)

Table 11 Homogeneous subset

\begin{tabular}{|c|c|c|c|c|}
\hline \multirow{2}{*}{\multicolumn{2}{|c|}{$\begin{array}{l}\text { Inhibition zone diameters Organism } \\
(\mathrm{cm}) \text {. }\end{array}$}} & \multirow[t]{2}{*}{$\mathbf{N}$} & \multicolumn{2}{|c|}{ Subset } \\
\hline & & & 1 & 2 \\
\hline \multirow{9}{*}{ Duncan $^{a, b}$} & Micrococcus luteus & 4 & .2500 & \\
\hline & Branhamella catarrhalis & 4 & .5250 & .5250 \\
\hline & Veillanella spp & 4 & .5575 & .5575 \\
\hline & Staphylococcus aureus & 4 & .8375 & .8375 \\
\hline & Candida albicans & 4 & .9575 & .9575 \\
\hline & Streptococcus mutans & 4 & & 1.1575 \\
\hline & Lactobacillus spp & 4 & & 1.1700 \\
\hline & Streptococcus pneumoniae & 4 & & 1.3450 \\
\hline & Sig. & & .107 & .070 \\
\hline
\end{tabular}

\section{Discussion}

The in-vitro antimicrobial assay of four (4) toothpaste (Sensodyne ${ }^{\circledR}$, Raiya ${ }^{\circledR}$, Mentadent ${ }^{\circledR}$ and Colgate ${ }^{\circledR}$ ) was tested against eight oral clinical isolates which includes strains of Streptococcus mutans, Brahamella catarrhalis, Veillonella spp, Micrococcus luteus, Lactobacillus spp, Staphylococcus aureus, Streptococcus pneumoniae and Candida albicans. These microbes are commonly found inhuman mouth (oral cavity) as microbial flora or pathogenic microbes before brushing the mouth [13].

The results of the antimicrobial assay of the different foreign toothpaste revealed that they were active against all the tested organisms. This agrees with the findings of Nascimento et al which stated that the active substance present in toothpastes kill microorganisms by disruptive activity, preventing bacterial aggression and slow bacterial multiplication [7]. However, among the selected toothpaste, Mentadent ${ }^{\circledR}$ had the highest zone of inhibition against the test organisms followed by Sensodyne ${ }^{\circledR}$ as shown in Table 6. Mentadent ${ }^{\circledR}$ toothpaste formulations includes zinc citrate and other additives in addition to fluoride, which is one of the major active component that helps to increase the 
antimicrobial activity of toothpaste. Scully and Bagan, reported that zinc citrate, triclosan and stannous fluoride reduce gingival inflammation and enhances the antimicrobial effect of toothpaste hence, can reduce the oral microbial load when used to wash or brush the mouth [5].

The result obtained from this research also revealed that Colgate ${ }^{\circledR}$ had the least antimicrobial activity against the tested organisms. This could be as a result of the continuous use of the toothpaste over a long period of time that has allowed the organisms to develop resistance against the active ingredients of the toothpaste. This was in agreement with [7] which revealed that microorganisms have the ability to develop resistant against antimicrobial substance when used for over a long period of time through genetic mutation or transfer of resistant gene and become resistant or less susceptible to the substance.

Among the eight organisms tested as shown in Table 9, Micrococcus luteus was the least inhibited having the lowest diameter of inhibition while Streptococcus pneumoniae had the highest mean value of $1.345 \mathrm{~cm}$. Streptococcus mutans which is one of the main opportunistic pathogens of dental caries [14], has an inhibition mean value of $1.158 \mathrm{~cm}$. This pathogen play central roles in fermenting carbohydrates resulting in acid production which could lead to demineralization of the tooth enamel [15]. In addition, Candida albicans which is usually associated with active caries lesions in immuno-compromised patients has an inhibition mean value of $0.958 \mathrm{~cm}$. Poor oral hygiene is also one of the reasons responsible for the growth of this microbe as well as their harmful activities. According to the research conducted by Ledder and his colleagues, the fungus (Candida albicans) was the most common yeast isolated from the oral cavity, infected root canals, showing resistance to inter-canal medication [16]. It causes oral thrush in which curdlike white patches formed inside the mouth, on the tongue and palate and around the lips of immuno-compromised persons, it may also cause cracked, red, moist areas of skin at the corners of the mouth [17]. Therefore, toothpaste as a mouth cleaning agent should be carefully selected and used twice daily as recommended by Dental Association in order to effectively maintain oral hygiene and prevent tooth decay.

\section{Conclusion}

The correlative in-vitro antimicrobial assay of various foreign toothpaste against oral microbial isolates showed that all the toothpaste selected for this study had antimicrobial properties but, Mentadent distinguish itself by having the highest zone of inhibition against the tested organisms because of its improved formulation of $2 \%$ zinc citrate. Therefore, Mentadent appears to be more effective than other selected toothpastes. There is an urgent need for toothpaste manufacturers to periodically review their formulations in order to improve the oral health of its users.

\section{Compliance with ethical standards}

\section{Acknowledgments}

Our profane gratitude goes to God Almighty and the entire staff of Microbiology Laboratory unit, Department of Science Laboratory Technology, Auchi Polytechnic, Auchi, Edo State for their support.

\section{Disclosure of conflict of interest}

The authors hereby declared that there was no conflict of interest in carrying out this research work.

\section{Statement of ethical approval}

The present research work does not contain any studies performed on animals/humans subjects by any of the authors.

\section{Statement of informed consent}

The present research work does not contain any information about any individual.

\section{References}

[1] Maltz M. (2009). Over-the-counter preventive and their apeutic Oral products. Braz Oral Res, 4-7.

[2] Davies R., Scully C and Preston AJ. (2010). Dentrifices: An update. Medical Oral Patol Oral or Bucal, 15(6), 82-976.

[3] Ersoy M, Tanalp J, Ozel E, Cengizlier R and Soyman M. (2008). The allergy of toothpaste: a case report in Allergol Immunopathol, 36(4), 70-368. 
[4] Jardim J, Alves L and Maltz M. (2009). The History and Global market of Oral home-care products. Braz Oral Res, 17-22.

[5] Scully C and Bagan JV. (2004). Adverse Drug Reactions in the Oral facial Region. CROBM, 15-221.

[6] Saeki Y, Ito Y, Shibata M, Sato Y, Okuda K and Takazoe I. (1989). Antimicrobial Action of Natural substances on Oral Bacteria. Bull Tokyo Dent Coll, 30(3), 129-135.

[7] Nascimento GGF, Locatelli J, Freitas PC and Silva GL. (2000). Antimicrobial activity of plant extract and phytochemical on antibiotic resistant bacteria, Brazilian, Microbiology, 31(4), 247-256.

[8] Lee SS, Zhang W and Yiming L. (2004). The antimicrobial potential of 14 natural herbal dentifrices. J Am Dent Assoc, 135(8), 1133-1141.

[9] Joiner A. (2006). Review of the extrinsic strain removal enamel/dentine abrasion by a Calcium Carbonate and perlite containing Whitening toothpaste. Int. Dent, (56), 175-180.

[10] Lin JT, Tsai CH, Yang LC and Chang YC. (2010). Clinical efficacy of phase 1 therapy combined with a Triclosan /Copolymer Dentrifice on generalized chronic periodontitis. Dent. Sci, 5, 20-216.

[11] Douglas LI. (2013). Candida Biofilms and their role in infection, Trend Microbial, 11, 30-36.

[12] Rahman M, Islam N, Islam MN and Hossain MS. (2015). Isolation and Identification of Oral bacteria and Characterization for Bacteriocin Production and Antimicrobial Sensitivity. Dhaka Univ. J. Pharm. Sci, 14(1), 103109.

[13] Singh S, Chaknis P, DeVizio W, Petrone M, Panagakos FS and Proskin HM. (2010). A Clinical investigation of the efficacy of three commercially available dentifrices for controlling established gingivitis and supragingival plaque, J. Clin. Dent, 21, 105-110.

[14] Sentila R, Gandhimathi A, Karthika S, Suryalakshmi R and Michael A. (2011). In vitro evaluation and comparison of the anti-microbial potency of commercially available oral hygiene products against Streptococcus mutans. J.Med. Sci, 65, 250-259.

[15] Sullivan RJ, Fletcher R, Bachiman R, Penugonda B and LeGeros RZ. (1995). Intra-oral comparison and evaluation of the ability of fluoride dentifrices to promote the remineralization of caries-like lesions in dentine and enamel, J. Clin. Dent, 6,135-138.

[16] Ledder RG, Latimer J, Humphrey GJ, Sreenivasan PK and McBain AJ. (2014). Bacteriological effects of dentifrices with and without active ingredients of natural origin, Journal of Applied Microbiol, 80(20), 6490-6498.

[17] McBain AJ, Sissons C, Ledder RG, Sreenivasan PK, DeVizio W and Gilbert P. (2005). Development and characterization of a simple perfused oral microcosm, Journal of Applied Microbiol, 98, 624-634.

\section{How to cite this article}

Oleghe PO, Agholor K, Olusola LF Abubakar I and Orhewere VA. (2020). Correlative antimicrobial assay of various foreign toothpaste against oral microbial isolates. World Journal of Advanced Research and Reviews, 7(1), $245-252$. 